\title{
Prevalência e sensibilidade aos antimicrobianos de Streptococcus suis sorotipo 2 em suínos abatidos em Mato Grosso
}

\author{
Prevalence and antimicrobial sensitivity profile of Streptococcus suis serotype 2 in slaughter pigs of Mato \\ Grosso
}

\author{
Juçara Tinasi de Oliveira ${ }^{1}$, Givago Faria Ribeiro da Silva², Daphine Ariadne Jesus de Paula ${ }^{2}$, Rosemari \\ Laura Cardoso ${ }^{2}$, João Garcia Caramori Júnior², Edson Moleta Colodel ${ }^{2}$, Luciano Nakazato² \& Valéria \\ Dutra²
}

\begin{abstract}
RESUMO
Streptococcus suis sorotipo 2 é um dos mais importantes patógenos de suínos, o qual traz significativas perdas econômicas em todo o mundo, além de ser um risco à saúde pública. O presente trabalho objetivou estudar a prevalência de Streptococcus suis sorotipo $2 \mathrm{em}$ tonsilas de suínos sadios em idade de abate e analisar o perfil de sensibilidade antimicrobiana das amostras isoladas. Foram coletadas 116 tonsilas de suínos abatidos provenientes de seis municípios de diferentes regiões de Mato Grosso. As amostras foram submetidas ao isolamento bacteriano e provas bioquímicas. Para a confirmação da espécie e sorotipo, foram realizadas as técnicas de PCR para os genes codificantes do $16 \mathrm{~S}$ rRNA e capsular cps $2 j$. O perfil de sensibilidade às drogas antimicrobianas foi realizado pelo método de difusão em disco, testando-se os seguintes antibióticos: ampicilina, lincomicina, norfloxacina, penicilina G, oxacilina e tetraciclina. Das 116 amostras analisadas, 17 foram positivas através do exame bacteriológico para o Streptococcus suis sorotipo 2, perfazendo uma prevalência de 14,65\%. Todas as amostras foram confirmadas através de PCR como sendo Streptococcus suis sorotipo 2. Dentre os antibióticos testados, a oxacilina e ampicilina foram os mais sensíveis, enquanto a lincomicina, tetraciclina, norfloxacina e penicilina $\mathrm{G}$ foram os mais resistentes.
\end{abstract}

Descritores: Streptococcus suis Sorotipo 2, Suíno Portador, Resistência, Mato Grosso.

\section{ABSTRACT}

Streptococcus suis serotype II is an important swine pathogen that causes significant economic looses worldwide and a public health concern. The aim of this study was to analyze Streptococcus suis serotype 2 prevalence in tonsils in swine slaughtered at Mato Grosso State and the antimicrobial resistance profile in the isolates. Were surveyed 116 tonsil samples collected from six cities in different areas of Mato Grosso. These samples were submitted to bacterial isolation and posterior biochemical test. To confirm bacterial specie and serotype, PCR were carried out to amplify $16 s$ rDNA and cps $2 j$ gene, respectively. The antimicrobial resistance profile was performed based on diffusion agar test to ampicillin, lincomycin, norfloxacin, penicillin G, oxacillin and tetracycline. Seventeen out of 116 samples were positive to S. suis type II resulting in a prevalence of $14.65 \%$. All samples were confirmed at species and serotype levels. In antibacterial resistance profile, oxacillin and penicillin were the most sensible while lincomycin, tetracycline, norfloxacin and penicillin were the more resistant.

Keywords: Streptococcus suis Type II, Carrier Pigs, Resistance, Mato Grosso. 
INTRODUÇÃO

As infecções causadas por Streptococcus suis são um grande problema da suinocultura mundial [18], principalmente onde a produção da carne suína é tecnificada [15]. Apesar da prevalência da doença ter sido estimada em aproximadamente $10 \%$, as perdas econômicas são bastante significativas, pois além dos gastos com tratamento, as taxas de mortalidade podem chegar a 20\% [11]. Nos suínos, o agente está associado a quadros clínicos de meningites, septicemias, polisserosites, artrites, endocardites, pneumonias e morte súbita e infecções nos seres humanos [14,24].

Atualmente, são reconhecidos 35 sorotipos (1 ao 34 e 1/2) [12,15,17], entretanto, o sorotipo 2 é o de maior prevalência em muitos países $[8,12,14]$, inclusive no Brasil, principalmente nas regiões sul e sudeste $[4,9,12,17]$.

A maior fonte de disseminação da doença são os próprios suínos portadores, que albergam o agente nas tonsilas e, ocasionalmente, na mucosa nasal [17,21]. Quando infectados, estes animais podem permanecer portadores por até seis meses [8].

Os antimicrobianos são importantes no tratamento, prevenção e controle da infecção por S. suis [27]. A resistência aos antimicrobianos mais utilizados tem sido descrita de forma crescente nas últimas décadas. Os estudos de sensibilidade a antimicrobianos deste microrganismo têm como foco apenas animais doentes e, raramente, tem-se avaliado isolados obtidos de animais clinicamente saudáveis [19].

Tendo em vista o aumento expressivo na criação de suínos no Estado de Mato Grosso nos últimos anos [2], este trabalho objetivou avaliar a prevalência de Streptococcus suis sorotipo 2 em suínos abatidos neste Estado, bem como verificar o perfil de resistência antimicrobiana.

\section{MATERIAIS E MÉTODOS}

Foram coletadas 116 amostras de tonsilas de suínos abatidos em três frigoríficos com Serviço de Inspeção Federal, durante os períodos de junho de 2005 a junho de 2007, em seis municípios de diferentes regiões do Estado de Mato Grosso. Esta amostragem foi baseada no programa EPI-Info 3.3.2 (2005) [13] considerando os seguintes parâmetros: número de animais abatidos no Estado no ano de 2006 (800.000) [1], prevalência estimada de 10,27\% [8], precisão absoluta de $9 \%$ e intervalo de confiança de 95\%. As tonsilas, uma vez colhidas, foram armazenadas individualmente em sacos plásticos, identificadas e encaminhadas em caixa isotérmica com gelo ao Laboratório de Microbiologia Veterinária para o processamento bacteriológico.

Após a retirada do excesso de gordura, as amostras foram mergulhadas em álcool, rapidamente flambadas e maceradas com solução salina $0,85 \%$. A suspensão foi inoculada em ágar sangue ovino $7 \%$ e ágar sangue azida, incubadas a $37^{\circ} \mathrm{C}$ durante 2448 horas. As colônias compatíveis com Streptococcus spp. foram repicadas e submetidas a provas bioquímicas para classificação [25].

Para confirmação da espécie e sorotipo foi realizada a técnica de PCR (Reação em Cadeia da Polimerase). Resumidamente, as colônias classificadas em S. suis sorotipo 2, através do isolamento, foram cultivadas em caldo infusão de cérebro e coração (BHI) por 24 horas a $37^{\circ} \mathrm{C}$. A extração do DNA genômico foi realizada conforme protocolo descrito por AUSUBEL (1999) [3]. A reação de PCR foi realizada utilizando os oligonucleotídeos iniciadores específicos para os genes do RNA ribossomal 16S (Sense 5'CAGTATTTACCGCATGGTAGATAT3' e Antisense 5'GTAAGATACCGTCAAGTGAGAA3') e capsular (cps2j) (Sense 5'GTTGAGTCCTTATACACCTGTT3' e Antisense 5'CAG AAAATTCATATTGTCCACC3'). A amplificação foi realizada conforme descrições de MAROIS (2004) [18]. Como controle positivo foi utilizada amostra de DNA de Streptocccus suis sorotipo 2, gentilmente cedida pela professora $\mathrm{Dr}^{\mathrm{a}}$. Agueda Castagna de Vargas (Laboratório de Bacteriologia Universidade Federal de Santa Maria).

A detecção dos produtos amplificados foi realizada através da eletroforese em gel de Agarose 1.5\%, corado com brometo de Etídio $(10 \mu \mathrm{g} / \mathrm{mL})$ e analisados em transiluminador. $\mathrm{O}$ marcador de massa molecular foi o ladder de 100pb.

O perfil de sensibilidade antimicrobiana foi realizado pelo método de Kirby-Bauer [14], testando-se as seguintes drogas antimicrobianas: ampicilina (AMP 10ug), lincomicina (LIN 02ug), norfloxacina (NOR 10ug), penicilina G (PEN 10ug), oxacilina (OXA 01ug) e tetraciclina (TET 30ug). Para determinar multi-resistência às drogas, foi utilizado o critério de que o microrganismo deveria apresentar resistência a duas ou mais classes de fármacos [16]. 


\section{RESULTADOS}

Das 116 amostras analisadas, 17 (14,65\%) foram positivas para Streptococcus suis sorotipo 2, através do isolamento bacteriológico. Dentro dos municípios analisados, as porcentagens de amostras positivas apresentaram uma variação de 17,24 a 33,33\% do total de animais estudados, conforme apresentado na Tabela 1. As amostras positivas pertenceram a três municípios (50\%). Dentre as amostras isoladas, todas foram confirmadas como sendo $S$. suis sorotipo 2 através das técnicas de PCR para o rRNA $16 \mathrm{~S}$ e capsular 2 e 1/2, conforme observado na Figura 1.

O perfil de sensibilidade aos antimicrobianos está sumarizado na Tabela 2. Observa-se que todas as amostras foram resistentes a lincomicina, em contrapartida, a
Figura 1. PCR para o gene capsular $c p s 2 j$ de tonsilas de suínos abatidos em frigoríficos de Mato Grosso no período de junho de 2005 a junho de 2007.

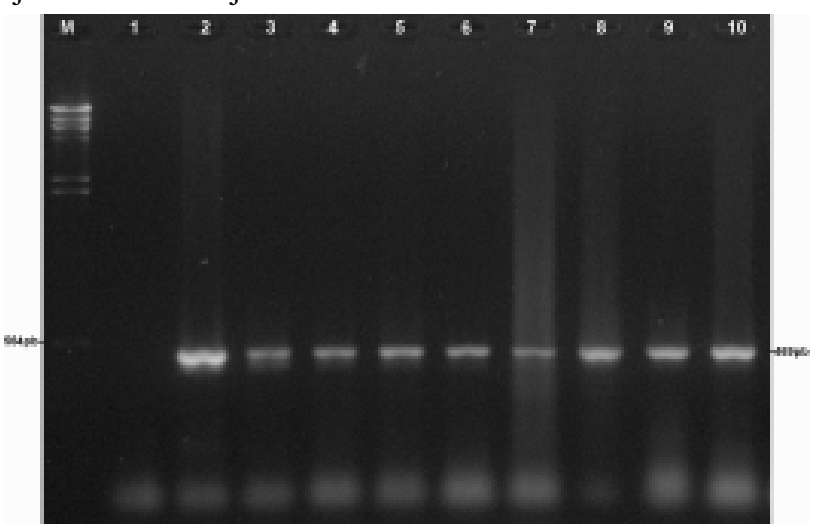

M. Marcador de massa molecular Lambda/Hind III; 1. Controle negativo; 2. Controle positivo para o gene capsular cps $2 \mathrm{j} ; 3$ 3-10. Amostras de animais portadores.

Tabela 1. Isolamento de Streptococcus suis sorotipo 2 de suínos abatidos em frigoríficos sob Inspeção Federal de Mato Grosso entre junho de 2005 a junho de 2007.

\begin{tabular}{|c|c|c|c|}
\hline \multirow{2}{*}{ Municípios } & \multicolumn{3}{|c|}{ Amostras } \\
\cline { 2 - 4 } & Pos $(\%)$ & Neg $(\%)$ & Total (\%) \\
\hline A & $10(17,24)$ & $48(82,76)$ & 58 \\
\hline B & 0 & $16(100,00)$ & 16 \\
\hline C & 0 & $15(100,00)$ & 15 \\
\hline D & 0 & $2(100,00)$ & 2 \\
\hline E & $4(25,00)$ & $12(75,00)$ & 16 \\
\hline F & $3(33,33)$ & $6(66,66)$ & 9 \\
\hline Total & $17(14,65)$ & $99(85,34)$ & $116(100,00)$ \\
\hline
\end{tabular}

Tabela 2. Perfil de sensibilidade de Streptococcus suis sorotipo 2 isolados de animais abatidos em frigoríficos sob Inspeção Federal de Mato Grosso entre junho de 2005 a junho de 2007.

\begin{tabular}{|c|c|c|c|}
\hline \multirow{2}{*}{ Antimicrobianos } & \multicolumn{3}{|c|}{ Perfil (\%) } \\
\cline { 2 - 4 } & $\mathrm{R}^{1}$ & $\mathrm{PS}^{2}$ & $\mathrm{~S}^{3}$ \\
\hline Ampicilina & 50,00 & 0 & 50,00 \\
\hline Lincomicina & 100,00 & 0 & 0 \\
\hline Norfloxacina & 75,00 & 6,25 & 18,75 \\
\hline Penicilina G & 68,75 & 12,50 & 18,75 \\
\hline Oxacilina & 43,75 & 0 & 56,25 \\
\hline Tetracilina & 81,25 & 0 & 18,75 \\
\hline
\end{tabular}

${ }^{1}$ Resistente, ${ }^{2}$ Parcialmente sensível e ${ }^{3}$ Sensível. 
oxacilina apresentou maior eficiência contra os isolados, sendo 56,25\% das amostras sensíveis a este antibiótico. Verificou-se, também, que houve resistência múltipla aos antimicrobianos testados em quatro isolados originários do mesmo município.

\section{DISCUSSÃO}

A detecção e identificação de Streptococcus suis sorotipo 2 em 14,65\% dos suínos abatidos e em $50 \%$ dos municípios analisados sugere que este microrganismo está presente no rebanho de Mato Grosso. Contudo, ao analisar-se a distribuição dos animais portadores somente nos municípios positivos, observou-se uma variação de $17,24 \%$ a $33,33 \%$, pois metade deles foi negativa ao isolamento. Condições sanitárias e de manejo adequadas, ausência de doenças concomitantes e baixas condições de estresse [4,5] para os suínos explicariam a ausência de $S$. suis sorotipo 2 em rebanhos de três municípios.

Os resultados obtidos através de exame bacteriológico de swabs tonsilares de suínos na região de Botucatu-SP concordam com este trabalho, porque, apesar dos autores terem encontrado prevalência inferior $(10,27 \%)$ [8], a ocorrência de $S$. suis sorotipo 2 entre as propriedades também oscilou de 0 a 33,33\%. No estado do Rio Grande do Sul, foi realizado um estudo visando detectar animais portadores de $S$. suis sorotipo 2 em tonsilas, em 1995. Neste estudo, analisou-se 239 tonsilas e observou-se 33,89\% das amostras positivas ao isolamento [4]. Em Santa Catarina, uma prevalência de $55,88 \%$ de lotes portadores foi descrita [17]. Nestes rebanhos, a prevalência variou entre 10 a 70\%, com média de 27,36\%. Esses índices são superiores aos encontrados em nosso estudo. Esta diferença poderia ser explicada pelo fato da região Sul ter uma suinocultura implantada há mais tempo, na qual os portadores já estariam inseridos no rebanho [4]. Outro fator seria o sistema de produção em ciclo completo, predominante no Mato Grosso [2], que influenciaria no nível sanitário do rebanho.

A prevalência de animais portadores de $S$. suis sorotipo 2 no Estado de Mato Grosso apresenta um nível inferior $(14,65 \%)$ quando comparado com estudos realizados em outros países [7,19,22,27]

Na França, em 2002, foram processadas 83 amostras de suínos doentes e 27 amostras de clinicamente saudáveis e, através de exames bacteriológicos e sorológicos, observou-se que dos isolados obtidos de animais clinicamente saudáveis, $44 \%$ pertenciam ao sorotipo 2 [19]. Em 1986, no Canadá, pesquisadores demonstraram a presença do agente em $8,1 \%$ em 347 suínos amostrados [6]. Em 2005, na Holanda, pesquisadores selecionaram 300 tonsilas de animais saudáveis e, destas, 54 (18\%) foram positivas para $S$. suis sorotipo 2 através da técnica de PCR. [26].

O perfil de sensibilidade de $S$. suis sorotipo 2 aos antimicrobianos avaliados no presente estudo foi similar a diversos estudos que analisaram isolados clínicos. Na Espanha, 87\% das amostras testadas foram resistentes à tetraciclina e lincomicina, entretanto, $89 \%$ foram sensíveis à penicilina G [27]. Na França, 100\% das amostras testadas foram sensíveis à penicilina $\mathrm{G} e$ apenas $19 \%$ e $30 \%$ das amostras foram sensíveis à tetraciclina e lincomicina, respectivamente [19]. No oeste do Canadá, todas as amostras (clínicas e de portadores) foram sensíveis a ampicilina. No mesmo estudo, todos as amostras clínicas e $87 \%$ das amostras de portadores foram resistentes à tetraciclina, e $2 \%$ e $3 \%$ das amostras clínicas foram resistentes à oxacilina e penicilina, respectivamente. Todas as amostras de portadores foram sensíveis a estes antibióticos [22]. Os resultados destes três países diferem deste trabalho apenas em relação à penicilina pois, em Mato Grosso, a sensibilidade do $S$. suis sorotipo 2 em relação a este antimicrobiano foi de apenas 18,75\%.

O perfil de sensibilidade encontrado neste estudo foi semelhante ao encontrado em outro estado brasileiro. Em 2000, na região de Botucatu-SP, 34 amostras de $S$. suis sorotipo 2 foram testadas frente a diferentes antibióticos e, destas, 92,86\% foram sensíveis à oxa-cilina, $85,72 \%$ à ampicilina, $7,14 \%$ à tetraciclina. Porém, diferentemente do presente estudo, a maioria dos isolados foi sensível à penicilina $\mathrm{G}(71,43 \%)$ [9].

A reduzida sensibilidade dos isolados de $S$. suis sorotipo 2 aos agentes antimicrobianos poderia ser explicada pelo uso intensivo destes fármacos na terapêutica e/ou profilaxia contra a infecção [27]. Esta também seria a explicação para a resistência múltipla em quatro isolados oriundos do mesmo município. Portanto, é muito importante o monitoramento da sensibilidade antimicrobiana antes do estabelecimento do tratamento nas propriedades [27].

A reduzida sensibilidade bacteriana às drogas antimicrobianas poderia estar relacionada à presença de plasmídeos, onde se localizam os genes mediadores de resistência. No oeste do Canadá, estudou-se o perfil de resistência a antibióticos e de plasmídeos em 
92 amostras de $S$. suis e observaram que $60(65,21 \%)$ pertenciam ao sorotipo 2 e destas, 47 (78,33\%) possuíam plasmídeos, sugerindo a presença de amostras "epidêmicas" na população de suínos [10].

A resistência da lincomicina pode ser mediada pela enzima conhecida como metilase resistente à eritromicina codificada pelo gene ermB. Na Holanda, em 2001, foram isoladas 87 amostras de S. suis de suínos doentes. Destas, $87 \%$ foram resistentes à lincomicina pelo método disco difusão e todas foram positivas para pesquisa do gene ermB pela PCR [22].
A presença deste gene poderia explicar a elevada resistência desta droga frente às amostras de Mato Grosso, porém, estudos futuros são necessários para comprovar esta hipótese.

\section{CONCLUSÃO}

Observou-se uma prevalência de $14,65 \%$ S. suis sorotipo 2 em portadores no Estado de Mato Grosso.

A sensibilidade dos isolados foi maior à oxacilina e ampicilina e menor à lincomicina tetraciclina, norfloxacina e penicilina $\mathrm{G}$.

\section{REFERENCIAS}

1 Abipecs. Associação Brasileira da Indústria Produtora e Exportadora da Carne suína. 2006. Disponível em: <http:// www.abipecs.org.br>. Acessado em 02/2008.

2 Acrismat. Associação dos Criadores de Suínos de Mato Grosso. 2008. Disponível em: 〈http://www.acrismat.com.br〉. Acessado em 02/2008.

3 Ausubel F.M., Brent R., Kingston R.E., Moore D.D., Seidman J.G., Smith J.A. \& Struhl K. 1999. Short protocols in molecular biology. 4th edn. New York: John Wiley and Sons, 600p.

4 Barcellos D., Borowski S.M. \& Oliveira S.J. 1995. Infecção de suínos pelo Streptococcus suis tipo II no Rio Grande do Sul: Pesquisa de portadores pelo exame bacteriológico de amígdalas coletadas em frigoríficos. Arquivos da Faculdade de Veterinária UFRGS. 23: 101-106.

5 Baums C.G., Verkuhlen G.J., Rehm T., Silva L.M.G., Beyerbach M., Pohlmeyer K. \& Valentin-Weigand P. 2007. Prevalence of Streptococcus suis Genotypes in Wild Boars of Northwestern Germany. Applied and Environmental Microbiology. 73: 711-717.

6 Breton J., Mitchell W.R. \& Rosendal S. 1985. Streptococcus suis I slaughter pigs and abattoir workers. The Canadian Journal of Veterinary Research. 50: 338-341.

7 Brisebois L.M., Charlebois R., Higgins R. \& Naudeau M. 1990. Prevalence of Streptococcus suis in four to eight week old clinically healthy piglets. The Canadian Journal of Veterinary Research. 54: 174-177.

8 Bosco S.M.G., Pezerico S.B., Cabral K.G., Silva A.V. \& Langoni H. 2000. Streptococcus suis tipo II em suínos e perfil de susceptibilidade a antimicrobianos. Arquivos do Instituto Biológico. 67: 157-160.

9 Calderaro F.F., Doto D.S., Baccaro M.R., Paixão R., Gomes C.R., de Castro A.F. P. \& Moreno A.M. 2004. Detecção dos genes codificadores das proteínas EF, MRP e suilisina em amostras de Streptococcus suis sorotipo 2 isoladas em suínos no Brasil. Arquivos do Instituto Biológico. 71: 15-19.

10 Cantin M., Harel J., Higgins R. \& Gottschalk M. 1992. Antimicrobial resistance patterns and plasmid profiles of Streptococcus suis isolates. Journal of Veterinary Diagnostic Investigation. 4: 170-174.

11 Cloutier G., D'Allaire S., Martinez G., Surprenant C., Lacouture S. \& Gottschalk M. 2003. Epidemiology of Streptococcus suis serotype 5 infection in a pig herd with and without clinical disease. Veterinary Microbiology. 97: 135-151.

12 Costa A.T.R., Lobato F.C.F., Abreu V.L.V., Assis R.A., Reis R. \& Uizal F.A. 2005. Serotyping and evaluation of the virulence in mice of Streptococcus suis strain isolated from diseased pigs. Revista do Instituto de Medicina Tropical. 47: 113-115.

13 Epi Info 2005. Disponível em: <http://www.lampada.uerj.br/epiinfo/download.htm>. Acessado em 03/2006.

14 Gottschalk M., Segura M. \& Xu J. 2007. Streptococcus suis infection in humans: the Chinese experience and the situation in North America. Animal Health Research Reviews. 8: 29-45.

15 Higgins R. \& Gottschalk M. 2006. Streptococcal disease. In: Straw, B.E.; Zimmerman, J.J.; D’Allaire, S. \& Taylor, D.J. Diseases of swine. 9. ed. Austrália: Blackwell publishing, pp.769-784.

16 Hofmann J., Cletron M.S., Farley M.M., Baughman W.S., Fackilam R.R., Elliott J.A., Deaver K.A. \& Breiman R.F. 1995. The prevalence of drug-resistant Streptococcus pneumoniae in Atlanta. The new England Journal of Medicine. 333 : 481-486. 
17 Lara A.C., Móres M.A.Z., Soncini R.A. \& Alberton G.C. 2007. Prevalência de Streptococcus suis sorotipo 2 em tonsilas de suínos sadios em idade de abate no estado de Santa Catarina. Archives of Veterinary Science. 12: 31-34.

18 Lun Z., Wung Q., Chen X., Li A. \& Zhu X. 2007. Streptococcus suis: an emerging zoonotic pathogen. Lancet Infection Disease. 7: 201-209.

19 Marie J., Morvan H., Berthelot-Hérault F., Sanders P., Kempt I., Gautier-Bouchardon A.V., Jony E. \& Kobisch M. 2002. Antimicrobial susceptibility of Streptococcus suis isolated from swine in France and from humans in different coutries between 1996 and 2000. Journal of Antimicrobial Chemotherapy. 50: 201-209.

20 Marois C., Bougeard S., Gottschalk M. \& Kobisch M. 2004. Multiplex PCR assay for detection of Streptococcus suis species and serotypes 2 e 1/2 in tonsils of live and dead pigs. Journal of Clinical Microbiology. 42: 3169-3175.

21 Marois C., Cariolet R., Morvan H. \& Kobisch M. 2008. Transmission of pathogenic respiratory bacteria to specific pathogen free pigs at slaughter. Veterinary Microbiology. 129: 325-332.

22 Martel A., Baele M., Devriese L.A., Goossens H., Wisselink H.J., Decostere A. \& Haesebrouck F. 2001. Prevalence and mechanism of resistance against macrolides and lincosamides in Streptococcus suis isolates. Veterinary Microbiology. 83: 287-297.

23 Morés N., Pierosan A.L. \& Amaral A.L. 2003. Fatores de risco associados com artrite em suínos de abate. Arquivo Brasileiro de Medicina Veterinária e Zootecnia. 55: 133-140.

24 Nghia H.D.T., Hoa N.T., Linh L.D., Campbell J., Diep T.S., Chau N.V.V., Nai N.T.H., Hien T.T., Spratt B., Farrar J. \& Schultsz C. 2008. Human case of Streptococcus suis serotype 16 infection. Emerging Infectious Diseases. 14: $155-157$.

25 Quinn P.J., Markey B.K., Carter M.E., Donnelly W.J. \& Leonard F.C. 2005. Streptococcus. In: Microbiologia Veterinária e Doenças Infecciosas. Porto Alegre: Artmed, pp. 61-66.

26 Swildens B., Wisselink H.J., Engel B., Smith H.E., Nielen M., Verheijden J.H.M. \& Stegeman J.A. 2005. Detection of extracellular factor-positive Streptococcus suis serotype 2 strains in tonsillar swabs of live sows by PCR. Veterinary Microbiology. 109: 223-228.

27 Vela A.I., Moreno A.M., Cebolla J.A., González S., Latre M.V., Domínguez L. \& Fernández-Garayzábal J.F. 2005. Antimicrobial susceptibility of clinical strains of Streptococcus suis isolated from pigs in Spain. Veterinary Microbiology. 105: 143-147. 